\title{
Tourist Satisfaction Factors via Analytic Hierarchy Process Decision Model on Cultural- Tourism in Kota Kinabalu, Sabah
}

\author{
Thavamalar Ramamoorty and Noraini Abdullah* \\ Faculty of Science and Natural Resources, Universiti Malaysia Sabah, \\ 88400 Kota Kinabalu Sabah, Malaysia
}

\begin{abstract}
In recent years, the tourism and hospitality industry has shown a deepening diversified growth and has become internationally a quick and growing industry that contributes the most in the economic development. Tourism plays a vital role in promoting a country's cultural and heritage, while cultural tourism covers all the travelling aspects, whereby the local people educate tourists with their own living ways, beliefs and thoughts. Other resources have stated that cultural tourism involves high values of places related to tourism, history and heritage. As there are several places in Sabah that exhibit great values in history and heritage of the local people, there is a need to evaluate the best decision-making of multiple criteria in the field of cultural tourism. Factors are identified using the Analytic Hierarchy Process (AHP) in terms of tourists' preferability, especially in the selection of cultural tourism spots in Sabah as their place of visitation. The objectives of this study are to evaluate and compare the preferability of tourists visiting the cultural-tourism locations, and to identify the significant factors that attract the tourists to visit these cultural-tourism spots. Prior to the data analysis, 150 respondents through questionnaires will be randomly selected at different cultural-tourism spots in Kota Kinabalu, Sabah. The data will be analysed using the AHP method, with the aid of Saaty 1-9 scale. The AHP decision model in this study was developed with the aid of model-building procedures like the normal matrix of z-scores and mean scores, and the pairwise comparison matrix of weights of criteria and sub-criteria. Based on the overall AHP analysis, it was found that the Destination criterion was ranked the highest at $52.51 \%$, followed by criterion of Benefits with weight of $22.36 \%$, partially ranked at $14.29 \%$ was Activities criterion, the criterion of Safety earned the weight $6.94 \%$, and lastly the lowest ranking for Services criterion at 3.90\%. From the analysis, it can be concluded that the most important factor in Cultural tourism was the Destination of the cultural spots.
\end{abstract}

Keywords: Cultural tourism, Analytic Hierarchy Process (AHP), tourists' preferability, significant factors, AHP decision model.

\section{INTRODUCTION}

In Malaysia, the arrival of tourists has been rapidly growing where in 2016 alone, tourist arrivals in the country had recorded 26.8 million arrivals, registering a total expenditure of MYR82.1 billion compared to the year 2015 where a turnover of 25.72 million tourist arrivals and MYR69.1 billion of expenditure only (WTTC, 2016). In addition, Tourism Malaysia has targeted an overall of 31.8 million arrivals and a total expenditure of MYR118 billion for 2017.
Cultural tourism covers all the travelling aspects whereby people travel to educate tourists with each other's living ways, their beliefs and thoughts (Roday et. al., 2009). Furthermore, tourism theoreticians agree to the oldest "birth certificates" of tours of cultural which include the explorations by ancient Greeks and Romans as well as the academic aspect (Mikos von Rohrscheidt, 2008). Hence, cultural tourism is namely the earliest type of tourism because of the rising growth of interest in culture in recent decades, whereby, there are numerous definitions addressing cultural tourism. 
In addition, such opinion as cultural tourism is travelling for vital cultural motivations and explorations was maintained longer and best illustrated by Medlik (1995) and Marczak (2000). Medlik (1995) stated that cultural tourism is motivated tours to places of artistic and historical value, visits to museums and galleries, journeys taken in order to participate in artistic performances and other cultural events where as Marczak (2000) argued that cultural tourism involves high value places related to tourism, history and heritage.

\section{MATERIALS AND METHODS}

The study was conducted at two main Cultural Tourism spots in Kota Kinabalu, Sabah. They were Sabah State Museum and Mari-Mari Cultural Village, because these tourists' spots mainly focus on diversity of Cultures in Sabah.

\section{A. Research Instrument}

This study required the help of computer software's to analyse the data. IBM software Statistical Package for Social Science (SPSS) version 24.0 and Microsoft Excel are the main software's used in this study. SPSS is a software used to analyse the research data that had been collected from 150 respondents. Among the functions of SPSS were entering and editing data, data cleaning, summarizing data on the frequency distribution table, descriptive statistics, graphical or Chart form, analysing the data through tests such as factor analysis and pairwise comparison.

Microsoft Excel was used to store all the data that have been analysed using SPSS by copying the results of SPSS and to calculate the synthetization, consistency and overall priority ranking for the Analytic Hierarchy Process (AHP). Microsoft Excel was used more in terms of data storage in a systematic way in order to process and understand the data analysis.

\section{B. Original Data}

The original data to be used in this study were the raw data obtained through the distribution of questionnaires to tourists at two selected cultural tourism spots. There were two sections in the questionnaire; Section A was mainly about the respondents' demographic profiles, and Section $\mathrm{B}$ was about the importance of criteria for the design of cultural tourism, according to the situation and requirement in Kota
Kinabalu.

The tourists were asked to assess the importance of cultural tourism design criteria on a scale ranging from (9 to 1). Respondent validity showed to determine how valid was the values obtained through these studies (Wells \& Wollack, 2003). The respondent validity can be determined through construct validity, where a similar concept questionnaire given to the same respondents and the results checked were related (Bolarinwa, 2015). About 30 tourists were randomly selected for initial distribution of the questionnaires as the pilot test. The alpha Cronbach value was determined by using the following formula (Wells \& Wollack, 2003):

$\hat{\alpha}=\frac{k}{k-1}\left(1-\frac{\sum_{i=1}^{k} p_{i}\left(1-p_{i}\right)}{\hat{\alpha}_{x}^{2}}\right)$

where,

$\mathrm{k}=$ number of variables

$p_{i}=$ proportions of the respondents who answered variable $\mathrm{i}$ correctly

$\hat{\alpha}_{x}^{2}=$ sample variance of total population

The closer the value of $\alpha$ to 1.00, the higher the consistency, and the more efficient the instrument used. Thus, we were using alpha value of 0.60 as the minimum acceptable reliability test (Nunnally \& Bernstein, 1994).

\section{Statistical analysis for the questionnaire from respondents}

In year 2008, Hines came up with a few statistical formulations to calculate the Arithmetic mean, Standard Deviation and Z-calculated (Hines et. al., 2008). The formulation to calculate the arithmetic mean and standard deviation for each criterion follows equations (2) and (3) respectively (Hines et al. 2008):

$$
\begin{aligned}
& \overline{\mathbf{x}}=\frac{\sum_{\mathrm{i}=1}^{\mathrm{k}} \mathrm{Xi} \cdot \mathrm{fi}}{\sum_{\mathrm{i}=1}^{\mathrm{k}} \mathrm{fi}} \\
& \mathbf{S}=\left[\frac{\sum_{i=1}^{k}(X i-\bar{x})^{2} * f i}{\left(\sum_{i=1}^{k} f i\right)}\right]^{1 / 2}
\end{aligned}
$$

where

$\overline{\mathrm{x}}$ : Arithmetic Mean

S: Standard Deviation

$\mathrm{Xi}$ : degree of importance for criterion

fi: Frequency of degrees

The purpose of Z-score in this study is to check the reliability of the questionnaire values (Hines et al. 2008). After finding the Arithmetic Mean and Standard Deviation, 
the quality of the survey result was tested with the $\mathrm{Z}$ test at a confidence level of $95 \%$. Using formula in (4), the $(Z$ calculated) for the criteria can then be calculated. The ( $Z$ calculated) were compared with (Z Tabular) at a confidence level of $95 \%$ to check the quality of the questionnaires results. At the end, if the ( $\mathrm{Z}$ calculate) is higher than the ( $\mathrm{Z}$ Tabular), we will accept the values of the questionnaire, and so is vice versa (Hassan \& Yahya, 2018).

$$
\text { Zcalculate }=\frac{\mathrm{x}}{\frac{s}{\sqrt{n}}}
$$

where

$\overline{\mathrm{x}}$ : Arithmetic Mean

S: Standard Deviation

n: sample size

"If $[\mathrm{Z}$ calculate $>\mathrm{Z}$ tabular $]$ then Accept the results of questionnaire" or wise versa.

\section{2. $\quad$ AHP decision model}

AHP is one way of making decisions and identify the location of the various criteria with a weighting of comparison in pairs. AHP also uses a hierarchical structure, allowing decision-makers to draw up criteria, sub-criteria and alternatives involved and so use a special matrix for a better assessment (Saaty, 2001). The decision-making process involves setting a higher priority and AHP are techniques that apply these principles. Typically, the individual preferences give profound effect on the results obtained.

The Hierarchical structure is important to develop criteria and sub-criteria which are involved; the hierarchy usually involves four stages, which were the objectives, criteria, sub-criteria and alternatives using a scale of 1 to 9 as in Table 1 (Saaty, 2005). Wang et. al., (2004) had defined AHP as a decision-making tool that analyzes or disassembles the complex problem into a multi-level hierarchical structures of goal, criteria, sub-criteria and alternatives. In general, AHP is to transform objective estimates of relative important into a set of degrees or total weights. With the aid of this method of fundamental property, which was based on the Pairwise Comparison, it complements the various quantitative and qualitative measures to combine them into one comprehensive degree that expresses the order of the alternative between a set of decision alternatives, as shown in Figure 1 below (Hines et. al., 2008; Saaty, 2005).

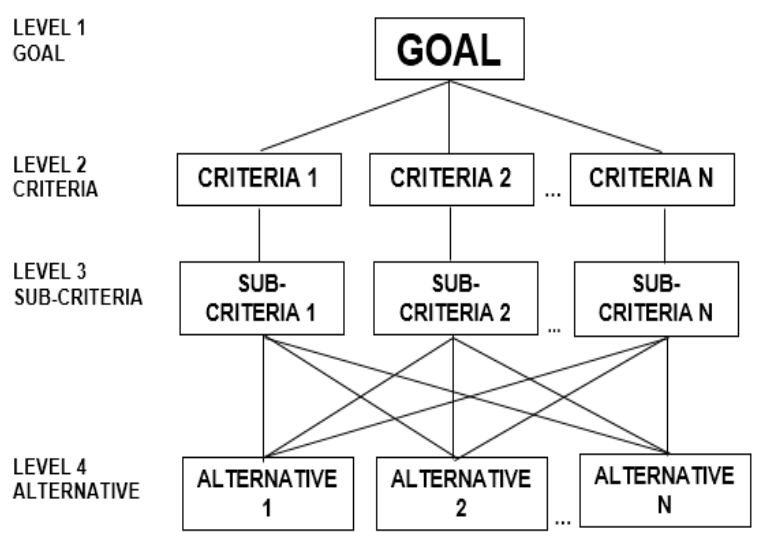

Figure 1. Analytic Hierarchy Process (AHP) model

Figure 2 depicts the hierarchical structure based on the multiple criteria and sub criteria used in this study for decision makers in the tourism industry.

Table 1. Fundamental scale of absolute numbers (Saaty, 2005)

\begin{tabular}{|c|l|l|}
\hline $\begin{array}{c}\text { Intensity of } \\
\text { Importance }\end{array}$ & \multicolumn{1}{|c|}{ Definition } & \\
\hline 1 & Equal Important & Two activities contribute equally to the objective \\
\hline 2 & Weak or Slight & \\
\hline 3 & Moderate Important & Experience and judgment slightly favour one activity over another \\
\hline 4 & Moderate plus & Experience and judgment strongly favour one activity over another \\
\hline 5 & Strong Important & or \\
\hline 6 & Strong plus & $\begin{array}{l}\text { An activity is favoured very strongly over another; its dominance } \\
\text { demonstrated in practice }\end{array}$ \\
\hline 7 & $\begin{array}{l}\text { Very strong } \\
\text { demonstrated important }\end{array}$ & $\begin{array}{l}\text { The evidence favouring one activity over another is of the higher possible } \\
\text { order of affirmation }\end{array}$ \\
\hline 8 & Very strong plus & Extreme importance
\end{tabular}




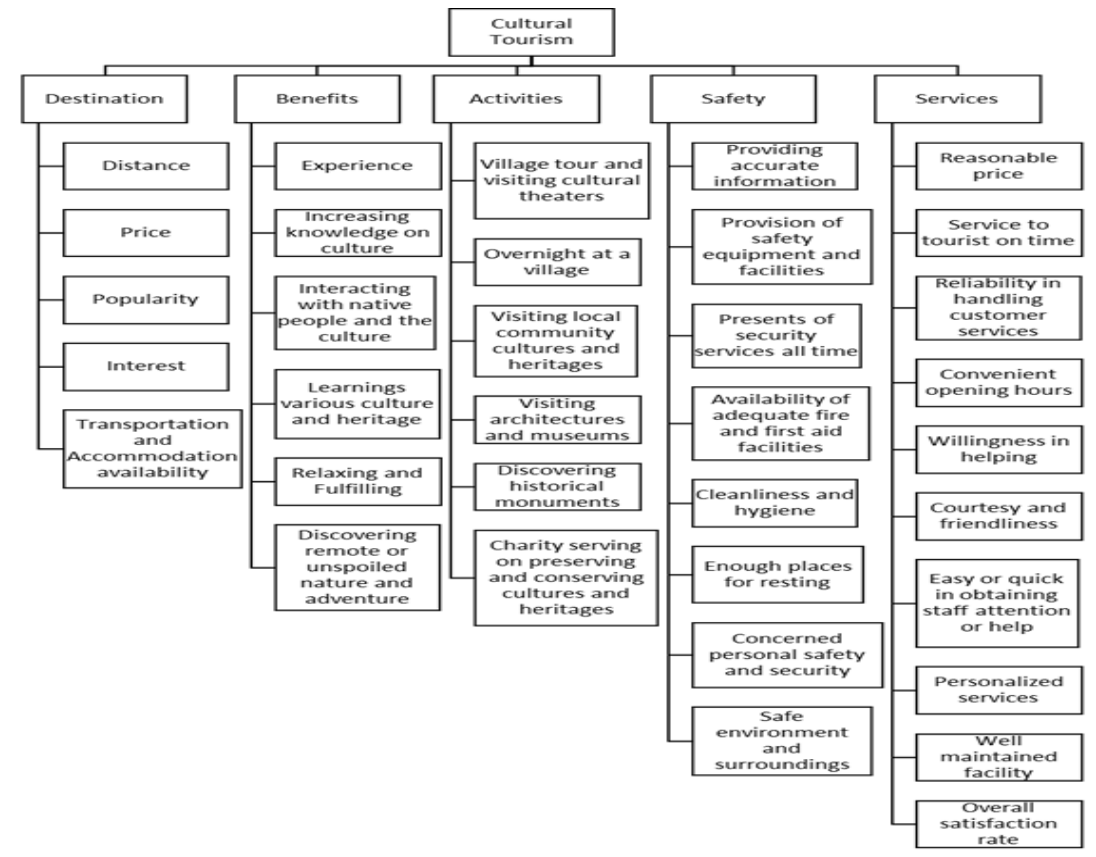

Figure 2. Building an AHP hierarchical decision model with multiple criteria.

\section{RESULTS AND DISCUSSIONS}

The results were obtained from analyses of data that had been gathered from the questionnaires from 150 respondents at the respective tourist hotspots in Kota Kinabalu, Sabah. The questionnaire undergoes statistical analysis before the AHP test. There were four main steps in the Analytic Hierarchy Process (AHP) as discussed in the methodology which were namely, constructed pairwise comparison matrix, building normal matrix, calculating the Weights, and consistency analysis will be shown clearly and explained. All these steps will identify the position of each criteria and sub-criteria according to the Weights respectively, and hence, the best criteria in contributing tourism industry can thus be determined.

\section{A. Reliability Statistics Results}

The questionnaire has been statistically analysed by firstly distributing the questionnaire as a pilot test to determine its reliability. Cronbach's Alpha is the most popular index which provides a measure of the extent to which the items on a test, each of which could be thought of as a mini-test providing consistent data regarding ones' mastery of the field (Bolarinwa, 2015).
Table 2. Cronbach alpha values

\begin{tabular}{|c|c|c|c|}
\hline \multicolumn{4}{|c|}{ Reliability Statistics } \\
\hline & $\begin{array}{c}\text { Cronbach's } \\
\text { Alpha }\end{array}$ & $\begin{array}{c}\text { N of } \\
\text { Items }\end{array}$ & $\begin{array}{c}\text { N of } \\
\text { respondents }\end{array}$ \\
\hline $\begin{array}{c}\text { Pilot } \\
\text { study }\end{array}$ & 0.966 & 74 & 30 \\
\hline $\begin{array}{c}\text { Total } \\
\text { survey }\end{array}$ & 0.983 & 74 & 150 \\
\hline
\end{tabular}

Cronbach alpha values were found to vary according to the number of respondents who participated in the pilot test, where the data from the questionnaires of 30 respondents had a Cronbach alpha of 0.966 which then had increased by 0.017 to 0.983 for the total 150 respondents of final data collected. Since both Cronbach values were more than 0.60, and were closer to 1.oo, thus, both Cronbach Alpha values were said to be reliable, and the questionnaire could thus be trusted and used for distribution.

\section{B. Statistical Analysis Results}

The values of the ( $Z$ Calculate) for criteria are shown in Table 3. The value of ( $Z$ Tabular) was equal to 1.645 at $95 \%$ level of confidence and sample size of 150 respondents. From the comparison between the (Z Calculate) and (Z Tabular), it can be noted that the values of ( $\mathrm{Z}$ Calculate) as shown in Table 3 for each criterion were all greater than the (Z Tabular). Since 
the values of ( $Z$ Calculate) were all higher than ( $Z$ Tabular), confidence level are acceptable and reliable.

thus these items in the questionnaire obtained at the $95 \%$

Table 3. Statistical Results for Questionnaire Items

\begin{tabular}{|c|c|c|c|}
\hline \multicolumn{4}{|c|}{ Descriptive Statistics } \\
\hline & Mean & Std. Deviation & Z Calculated \\
\hline Destination & 6.61 & 2.049 & 39.5098 \\
\hline Distance & 6.33 & 2.048 & 37.8547 \\
\hline Price & 6.27 & 2.260 & 33.9785 \\
\hline Popularity & 6.58 & 1.964 & 41.0327 \\
\hline Interest & 7.09 & 2.000 & 43.4172 \\
\hline Transportation and Accommodation availability & 6.74 & 1.971 & 41.8812 \\
\hline Benefits & 6.67 & 1.946 & 41.9787 \\
\hline Experience & 6.74 & 1.985 & 41.5858 \\
\hline Increasing knowledge on culture & 6.44 & 1.826 & 43.1947 \\
\hline Interacting with native people and the culture & 6.29 & 2.018 & 38.1747 \\
\hline Learnings various culture and heritage & 6.19 & 2.160 & 35.0980 \\
\hline Relaxing and Fulfilling & 7.45 & 1.595 & 57.2060 \\
\hline Discovering remote or unspoiled nature and adventure & 6.65 & 2.063 & 39.4792 \\
\hline Activities & 6.43 & 1.991 & 39.5535 \\
\hline Village tour and visiting cultural theaters & 6.46 & 1.965 & 40.2015 \\
\hline Overnight at a village & 5.93 & 2.244 & 32.3651 \\
\hline Visiting local community cultures and heritages & 5.98 & 2.074 & $35 \cdot 3133$ \\
\hline Visiting architectures and museums & 6.61 & 1.787 & $45 \cdot 3025$ \\
\hline Discovering historical monuments & 6.91 & 1.783 & 47.4649 \\
\hline Charity serving on preserving and conserving cultures and heritages & 6.09 & 2.130 & 35.0174 \\
\hline Safety & 6.75 & 1.891 & 43.7178 \\
\hline Providing accurate information & 6.39 & 1.903 & 41.1252 \\
\hline Provision of safety equipment and facilities & 6.76 & 1.729 & 47.8848 \\
\hline Presents of security services all time & 6.59 & 1.836 & 43.9601 \\
\hline Availability of adequate fire and first aid facilities & 6.46 & 1.870 & 42.3094 \\
\hline Cleanliness and hygiene & 6.99 & 1.770 & 48.3670 \\
\hline Enough places for resting & 6.85 & 1.779 & 47.1585 \\
\hline Concerned personal safety and security & 7.09 & 1.804 & 48.1344 \\
\hline Safe environment and surroundings & 7.02 & 1.782 & 48.2475 \\
\hline Services & 6.99 & 1.797 & 47.6403 \\
\hline Reasonable price & 7.13 & 1.903 & 45.8877 \\
\hline Service to tourist on time & 6.66 & 1.690 & 48.2651 \\
\hline Reliability in handling customer services & 6.41 & 1.711 & 45.8832 \\
\hline Convenient opening hours & 6.89 & 1.643 & 51.3603 \\
\hline Willingness in helping & 7.01 & 1.770 & 48.5054 \\
\hline Courtesy and friendliness & 7.08 & 1.645 & 52.7124 \\
\hline Easy or quick in obtaining staff attention or help & 6.92 & 1.608 & 52.7067 \\
\hline Personalized services & 6.89 & 1.673 & 50.4393 \\
\hline
\end{tabular}




\begin{tabular}{|l|l|l|l|}
\hline Well maintained facility & 7.06 & 1.692 & 51.1034 \\
\hline Overall satisfaction rate & 6.95 & 1.962 & 43.3842 \\
\hline
\end{tabular}

\section{Weights of Main Criteria Results}

After the statistical results had been analysed, the weights of criteria are specified for cultural tourism. This will be found by using AHP, which will produce pairwise comparison between the criteria depending on the values of the arithmetic mean, as in Table 3.
Table 4 below shows the matrix of pairwise comparison for the criteria. The end result of the questionnaires used via AHP is shown in Table 5. This gave priorities (or weights) of criteria with respect to the goal, and the weights of subcriteria with respect to the main criteria and sub-criteria respectively.

Table 4. Pairwise Comparison Matrix of Main Criteria

\begin{tabular}{|l|l|l|l|l|l|}
\hline \multicolumn{7}{|c|}{ Pairwise comparison } \\
\hline & Destination & Benefits & Activities & Safety & Services \\
\hline Destination & 1 & 3 & 5 & 9 & 9 \\
\hline Benefits & $1 / 3$ & 1 & 4 & 2 & 5 \\
\hline Activities & $1 / 5$ & $1 / 4$ & 1 & 3 & 6 \\
\hline Safety & $1 / 9$ & $1 / 2$ & $1 / 3$ & 1 & 2 \\
\hline Services & $1 / 9$ & $1 / 5$ & $1 / 6$ & $1 / 2$ & 1 \\
\hline
\end{tabular}

Table 5. Weights of main criteria and sub-criteria for Cultural tourism spots

\begin{tabular}{|c|c|c|}
\hline Criteria & \multicolumn{2}{|c|}{ Priorities (Weights) } \\
\hline \multicolumn{3}{|l|}{ Inconsistency $=0.08607$} \\
\hline Main Criteria for Ecotourism & Weight & Ranking \\
\hline Destination & 0.52513 & 1 \\
\hline Benefits & 0.22359 & 2 \\
\hline Activities & 0.14289 & 3 \\
\hline Safety & 0.06935 & 5 \\
\hline Service & 0.03904 & 4 \\
\hline \multicolumn{3}{|l|}{ Sub Criteria for Destination } \\
\hline \multicolumn{3}{|l|}{ Inconsistency $=0.09249$} \\
\hline Distance & 0.07479 & 4 \\
\hline Price & 0.03338 & 5 \\
\hline Popularity & 0.11787 & 3 \\
\hline Interest & 0.43503 & 1 \\
\hline Transportation and Accommodation availability & 0.33894 & 2 \\
\hline \multicolumn{3}{|l|}{ Sub Criteria for Benefits } \\
\hline \multicolumn{3}{|l|}{ Inconsistency $=0.04710$} \\
\hline Experience & 0.20745 & 3 \\
\hline Increasing knowledge on culture & 0.09235 & 4 \\
\hline Interacting with native people and the culture & 0.03541 & 6 \\
\hline Learning various culture and heritage & 0.03719 & 5 \\
\hline Relaxing and fulfilling & 0.37366 & 1 \\
\hline
\end{tabular}




\begin{tabular}{|c|c|c|}
\hline Discovering remote or unspoiled nature and adventure & 0.25393 & 2 \\
\hline \multicolumn{3}{|l|}{ Sub Criteria for Activities } \\
\hline \multicolumn{3}{|l|}{ Inconsistency $=0.08114$} \\
\hline Village tour and visiting cultural theatres & 0.47635 & 1 \\
\hline Overnight at a village & 0.04570 & 5 \\
\hline Visiting local community cultures and heritages & 0.06579 & 4 \\
\hline Visiting architectures and museums & 0.02710 & 6 \\
\hline Discovering historical monuments & 0.13242 & 3 \\
\hline Charity service on preserving and conserving cultures and heritages & 0.25265 & 2 \\
\hline \multicolumn{3}{|l|}{ Sub Criteria for Safety } \\
\hline \multicolumn{3}{|l|}{ Inconsistency $=0.08586$} \\
\hline Providing accurate information & 0.01968 & 8 \\
\hline Provision of safety equipment and facilities & 0.06011 & 5 \\
\hline Presents of security services all time & 0.03385 & 6 \\
\hline Availability of adequate fire and first aid facilities & 0.03013 & 7 \\
\hline Cleanliness and hygiene & 0.33515 & 1 \\
\hline Sufficient places for resting & 0.18060 & 3 \\
\hline Concerned personal safety and security & 0.11931 & 4 \\
\hline Safe environment and surroundings & 0.22117 & 2 \\
\hline \multicolumn{3}{|l|}{ Sub Criteria for Service } \\
\hline \multicolumn{3}{|l|}{ Inconsistency $=0.09657$} \\
\hline Reasonable price & 0.24776 & 1 \\
\hline Service to tourist on time & 0.21244 & 2 \\
\hline Reliability in handling customer services & 0.11796 & 4 \\
\hline Convenient opening hours & 0.12168 & 3 \\
\hline Willingness in helping & 0.09419 & 5 \\
\hline Courtesy and friendliness & 0.07172 & 6 \\
\hline Easy or quick in obtaining staff attention or help & 0.04532 & 7 \\
\hline Personalized services & 0.03525 & 8 \\
\hline Well maintained facility & 0.02706 & 9 \\
\hline Overall satisfaction rate & 0.02661 & 10 \\
\hline
\end{tabular}

Based on Table 5, the highest weight is received by the Destination criterion which is of $52.51 \%$ (highlighted in yellow). This indicates that this criterion is of great importance from the point of view of the tourists who visited these selected Cultural Tourism spots.

In the second place is the criterion of Benefits, which obtained a weight of $22.36 \%$. It deserves this rank of importance because of its significant impact on in Cultural Tourism spots. The criterion of Activities, which earnes the weight of $14.29 \%$ is in a moderate proportion. The criterion of Safety earns the weight $6.94 \%$, which is a medium proportion, and lastly the criterion of Services which obtains a proportion of importance of almost $3.90 \%$, which is of a lower proportion. This proportion give an indication of less importance of compared to the other criteria in the Cultural Tourism Sector.

When doing a pairwise comparison between criteria in AHP, the inconsistency index equals to 0.08607 (highlighted in blue), which is less than the highest value (o.1). Hence, it is satisfactory according to the AHP conditions and requirements. The same goes to the sub-criteria in identifying the priorities, the inconsistency index for all comparison is less than 0.1. This demonstrates the possibility of depending on the judgment that have been received in the pairwise comparison for the main and sub criteria.

So far there is no other research that had been done before on cultural tourism in Sabah by using the AHP model 
for decision making. However, there is a similar research done by Hassan \& Yahya (2018) where they used AHP to assess the importance of design criteria for school buildings project in Iraq. They distributed questionnaires to 49 respondents where the authors used $\mathrm{Z}$ test to find out the quality of the questionnaire results at the 95\% confidence level. At the end of the $\mathrm{Z}$ test all their ( $\mathrm{Z}$ Calculate) values were higher than the ( $Z$ Tabular) value of 1.684; thus, their questionnaire results were used for AHP. After the AHP analysis, they found out that the most important criteria in the School building design was the Performance criteria which had the highest weight as compared to the other criteria, and at the same time, the Inconsistencies index for the Main criteria was 0.03294 which was less than 0.1. Therefore, the results of this study can be said to be similar to Hassan \& Yahya (2018).

The sub-criteria for each criterion had also been ranked according to their weightage. Sub-criteria for Destination were ranked as followings; interest (43.5\%), transportation and accommodation (33.9\%), popularity (11.8\%), distance (7.5\%), and price (3.3\%). The sub-criteria for Benefits were ranked as followings; relaxing and fulfilling (37.4\%), discovering remote or unspoiled nature and adventure (25.4\%), experience (20.7\%), increasing knowledge on culture (9.2\%), learning various culture and heritage (3.7\%), and interacting with native people and the culture (3.5\%).

Sub-criteria for Activities were ranked as followings; village tour and visiting cultural theatres (47.6\%), charity service on preserving and conserving cultures and heritage (25.3\%), Discovering historical monuments (13.2\%), Visiting local community cultures and heritages (6.6\%), Overnight at a village (4.6\%), and Visiting architectures and museums (2.7\%). Sub-criteria's ranking for Safety were as followings; Cleanliness and hygiene (33.5\%), Safe environment and surroundings (22.1\%), Sufficient places for resting (18.1\%), Concerned personal safety and security (11.9\%), Provision of safety equipment and facilities (6.0\%), Presence of security services all time (3.4\%), Availability of adequate fire and first aid facilities (3.0\%), and Providing accurate information (2.0\%).

Lastly, ranking of sub-criteria's for services were as followings; Reasonable price (24.8\%), Service to tourist on time (21.2\%), Convenient opening hours (12.2\%), Reliability in handling customer services (11.8\%), Willingness in helping (9.4\%), Courtesy and friendliness (7.2\%), Personalized services (3.5\%), Well maintained facility (2.7\%), and Overall satisfaction rate (2.7\%).

\section{CONCLUSION}

As a conclusion, the criteria that had been ranked from the high to the lower weightage were: Destination $=>$ Benefits $=>$ Activities => Safety $=>$ Services respectively. From observations too, tourists visited these cultural spots because of the vicinity of the Destination of the spots to the Kota Kinabalu International Airport (KKIA), hence saves tourists' traveling time and costs to these cultural spots.

\section{ACKNOWLEDGEMENT}

The authors would like to thank the Centre for Research and Innovation, Universiti Malaysia Sabah for funding this project to be successfully completed via UMS Great (GUG0243-1/2018). 


\section{REFERENCES}

Bolarinwa, O.A. 2015, Principles and Methods of Validity and Reliability Testing of Questionnaires Used in Social and Health Science Researches. Nigerian Postgraduates Medical Journal. vol. 22, no. 4, pp.195-201.

Hassan M.A \& Yahya H.M. 2018, "Building an AHP decision model to assess the importance of design criteria for school building projects in Iraq”, vol. 5, no. 3, pp.1-11.

Hines, William W., Douglas C. Montgomery, \& David M. Goldman Connie M. Borror. 2008, "Probability and statistics in engineering”, John Wiley \& Sons.

Marczak M. 2000, Rodzaje turystyki, [in:] A. Szwichtenberg, (red.) Podstawy turystyki, Politechnika Koszalińska, Koszalin.

Medlik S. 1995, Leksykon podróży, turystyki, hotelarstwa, PWN, Warszawa.

Mikos von Rohrscheidt A. 2008, Turystyka kulturowa. Fenomen, potencjal, perspektywy, GWSHM Milenium, Gniezno.

Nunnally J.C. \& Bernstein, J.H. 1994, Psychometric Theory (3rd ed.). New York;17, 275-280. feedback. Pittsburgh: RWS Publications.

Roday, Sunetra, Biswal, Archana and Joshi Vandana. 2009, “Tourism Operations and Management, Third Edition, Oxford University Press, New Dehli. P173.
Saaty, T. 2001, The analytic network process: decision making with dependence and feedback. Pittsburgh: RWS Publications.

Saaty, T. 2005, The analytic hierarchy and analytic network processes for the measurement of intangible criteria and for decision making. In: Figueira J, Greco S, Ehrgott M, editors. Multiple criteria decision analysis state of the art surveys. ccNew York: Springer Science + Business Media, Inc.

Wang, Ge, Samuel H. Huang, \& John P. Dismukesa. 2004, Product-driven supply chain selection using integrated multi-criteriadecision-making methodology. Int. J. Production Economics, vol. 91, pp. 1-15.

Wells, C.S. \& Wollack, J.A. 2003, An Instructor's Guide to Understanding Test Reliability. Testing \& Evaluation Services. University of Wisconsin.

World Travel and Tourism Council (WTTC). 2006, Malaysia: Travel and Tourism Climbing to New Heights. World Travel and Tourism Council, London. 